\title{
The Experts Have Spoken!: A Reply to Four Commentaries
}

\author{
Amel Becirevic
}

Published online: 9 January 2015

(C) Association for Behavior Analysis International 2015

\begin{abstract}
Four prominent behavior analysts provided advice to graduate students when attempting to correct misunderstandings about behavior analysis. This article briefly summarizes the four commentaries.
\end{abstract}

Keywords Misunderstanding $\cdot$ Dissemination $\cdot$ Advice $\cdot$ Behavior analysis

In the previous issue of Behavior Analysis in Practice, I shared the findings of a survey about responding to misrepresentations of behavior analysis (Becirevic 2014), and I asked about appropriate steps that graduate students should take when they encounter misrepresentations. Oh, how my distress call was answered! Four prominent behavior analysts quickly fired back with advice. Critchfield (2014) shared ten maxims that every behavior analyst should consider when dealing with people who misunderstand the field. Todd (2014) referred behavior analysts to two sources, Judith Martin's Miss Manner's Guide to Excruciatingly Correct Behavior (1982) and Dale Carnegie's How to Win Friends and Influence People (1936), as a way to educate ourselves when communicating and providing feedback. Being cognizant of the context and addressing misconceptions in a professional and non-

This comment refers to the article available at: http://dx.doi.org/10.1007/ s40617-014-0019-y.

\footnotetext{
A. Becirevic $(\square)$

Department of Applied Behavioral Science, University of Kansas, 4085 Dole Human Development Center, 1000 Sunnyside Avenue, Lawrence, KS 66045-7555, USA

e-mail: amel@ku.edu
}

argumentative manner, according to Zarcone (2015), is the difference between success and failure of swaying the opinions of others. Finally, Schlinger (2014) stressed that graduate students can best learn and explain the experimental and theoretical foundations of our field when their graduate programs hire faculty who were specialized in these areas. After all, the repertoires of graduate students are shaped by the faculty and the orientations of the academic programs.

Effectively communicating with outsiders of the field was the main point that all four authors made. Another point becomes apparent: misunderstandings and communication consist of complicated verbal repertoires, and as such, verbal behavior lies within the subject matter of behavior analysis. Therefore, behavior analysts should consider the vast reinforcement history of the audience, especially if the individual has little or no knowledge about behavior analysis. Having a thorough understanding of our field and while simultaneously possessing the verbal repertoire for communicating with outsiders are both skills that require patience and practice. These valuable skills require practice, lots of practice, but the payoff will be worth it.

\section{References}

Becirevic, A. (2014). Ask the experts: How can new students defend behavior analysis from misunderstandings? Behavior Analysis in Practice, 7, 138-140. doi:10.1007/s40617-014-0019-y.

Critchfield, T. S. (2014). Ten rules for discussing behavior analysis. Behavior Analysis in Practice, 7, 141-142. doi:10.1007/s40617014-0026-z.

Schlinger, H. D. (2014). Training graduate students to effectively disseminate behavior analysis and to counter misrepresentations.

Todd, J. T. (2014). Some useful resources for students who are tempted to bring enlightenment to errant non-behaviorists. Behavior Analysis in Practice, 7, 143-144. doi:10.1007/s40617-014-0027-y.

Zarcone, J. (2015). Ask the Experts: Answer to: How Can New Students Defend Behavior Analysis from Misunderstandings? doi:10.1007/ s40617-014-0037-9 